\title{
ACTIVITY OF SERINE PROTEASES FROM FASCIOLA HEPATICA EGGS IN RELATION TO PH AND TEMPERATURE
}

\author{
L. KIANIFARD ${ }^{1}$, M. YAKHCHALI ${ }^{1} \&$ M. IMANI ${ }^{2}$ \\ ${ }^{1}$ Department of Pathobiology, ${ }^{2}$ Department of Basic Sciences; \\ Faculty of Veterinary Medicine, Urmia University, Urmia, Iran
}

\begin{abstract}
Summary
Kianifard, L., M. Yakhchali \& M. Imani, 2020. Activity of serine proteases from Fasciola hepatica eggs in relation to $\mathrm{pH}$ and temperature. Bulg. J. Vet. Med., 23, No 3, 350-358.

This study was conducted to analyse the serine protease of Fasciola hepatica eggs by specific substrates and inhibitors, and investigation of the effects of $\mathrm{pH}$ and temperature on proteases' activity and stability. Adult worms were isolated from infected livers. After homogenisation, their protein levels were measured with the Bradford method. Total proteolytic activity of the Fasciola hepatica extract was evaluated with azocasein substrate at $\mathrm{pH}$ values from 2 to 12 . N-benzoyl-arginine- $\mathrm{p}$ nitroanilide (BApNA) trypsin and N-succinyl-alanine-alanine-prolin-phenylalanine-p-nitroanilide (SAAPFpNA) chymotrypsin substrates were used to measure specific protease activities. The effect of protease inhibitors phenylmethane sulfonyl fluoride (PMSF), pepsin, and ethylenediaminetetraacetic acid (EDTA) on these enzymes was evaluated. Estimation of optimum temperature and $\mathrm{pH}$ was performed in the temperature range of $10-90{ }^{\circ} \mathrm{C}$ and $\mathrm{pH}$ values from $2-12$. The optimum $\mathrm{pH}$ activities for trypsin and chymotrypsin were at alkaline $\mathrm{pH}$ and for total proteolytic activity at acidic $\mathrm{pH}$. The results using protease inhibitors showed that the eggs had serine protease activity. The optimum temperature activity of trypsin and chymotrypsin was $50{ }^{\circ} \mathrm{C}$. These proteases were stable up to $40{ }^{\circ} \mathrm{C}$. Due to the importance of $\mathrm{pH}$ and temperature in life cycle of Fasciola hepatica, these findings can be used for induction of some modifications in $\mathrm{pH}$ and preventing the activity of the enzyme for decrement of the efficacy of embryonic development and egg hatching of this zoonotic parasite.
\end{abstract}

Key words: Fasciola hepatica, pH, serine protease, stability, temperature

\section{INTRODUCTION}

Fasciolosis is a worldwide disease in humans and animals caused by the digenean trematode Fasciola hepatica (Yakhchali \& Bahramnejad, 2016). The World Health Organization recognises fasciolosis as a major food-borne disease, with up to 17 million human cases in 61 countries and 180 millions at risk for fasciolosis (Mas-
Coma, 2005). Fasciolosis is also known as a common parasitic infection which leads to significant loss in growth and meat production in livestocks in Europe, Africa, Asia, the Americas and Australasia and annual economic losses of more than USD 3 billion (Mas-Coma, 2005). 
Proteases are essential for parasites and facilitate important activities such as invasion, hatching, excystment, nutrition and helminth fecundity and immune evasion (Horn et al., 2014; Dvorak et al., 2016). They are a target for vaccine and drug production (Tallima et al., 2017). Most studies are concentrated on cysteine and aspartic proteases of Fasciolidae (McVeigh et al., 2012). The largest family of proteases are serine proteases and their function is critical in many occurrences (Rawlings et al., 2016). They are important in the life cycles of a wide range of helminths (Yang et al., 2015). Serine proteases are expressed in newly excysted larvae, immature, mature flukes and are involved in penetration and tissue migration (Sajid \& McKerrow, 2002). Dipeptidylpeptidase (DPP) has been isolated from $F$. hepatica (Carmona et al., 1993). DPP is secreted by newly excysted juveniles, immature and mature flukes. It was recognised as a serine protease by the specific substrate and a slightly acidic $\mathrm{pH}$ optimum. The prolyl carboxypeptidase was identified from the proteins secreted by 21 days old immature and adult $F$. hepatica (Robinson et al., 2009). Environmental factors such as $\mathrm{pH}$ and temperature are critical for $F$. hepatica's life cycle including penetration, invasion, tissue migration, embryonic development and egg hatching (Hurtrez-Boussès, 2001; Yakhchali \& Bahramnejad, 2016).

Most studies of Fasciola proteases were concentrated on $F$. hepatica and F. gigantica proteases from adult and newly excysted juveniles and very little information was reported on the proteases from $F$. gigantica eggs. The laboratory assessment of the impact of $\mathrm{pH}$ and temperature on the serine proteases activity in the extract of $F$. hepatica eggs can be useful in further understanding of the degree of their effects in natural environments. This study was aimed at evaluating the serine proteases in the extract of $F$. hepatica eggs with substrates and determination of the optimum $\mathrm{pH}$ for enzyme activity. The inhibitory patterns of proteases were evaluated by protease inhibitors.

\section{MATERIALS AND METHODS}

\section{Helminth sampling and egg collection}

A number of $250 F$. hepatica adult worms were isolated from naturally infected livers of the slaughtered cattle. The livers were cut into small pieces and the adult helminths were removed from the bile ducts. F. hepatica was saved directly in an ice box during transportation to the laboratory. The isolated Fasciola were examined for the presence of eggs by microscopic inspection. The fertile helminths were crushed in a mortar containing 10 $\mathrm{mL}$ of distilled water and sieved to gather the eggs. The eggs were washed several times using $0.086 \%$ Ringer's solution and centrifuged at $445 \times \mathrm{g}$ for $5 \mathrm{~min}$ to remove debris. The supernatant was discarded and the precipitated eggs were washed three times (Yakhchali \& Bahramnejad, 2016).

\section{Protease activity assays}

The eggs were homogenised by grinding in liquid nitrogen eight times to access total cytosolic proteins, then centrifuged at $16,000 \times \mathrm{g}$ for $10 \mathrm{~min}$ at $4{ }^{\circ} \mathrm{C}$, and the supernatant was collected as the extract. The protein concentration of the supernatant was determined by the Bradford method (Bradford, 1976). The pH optimums were determined for the extracts of egg's protease activities using $\mathrm{pH}$ values from 2 to 12 . General proteolysis was assessed with azocasein as substrate (Elpidina et al., 2001). The reaction mix- 
ture including $30 \mu \mathrm{L}$ azocasein $2 \%, 90 \mu \mathrm{L}$ universal buffer (acetate-phosphate-sodium borate $50 \mathrm{mM}$ ) at different $\mathrm{pH}$ from 2 to $12,15 \mu \mathrm{L}$ extract was incubated at 36 ${ }^{\circ} \mathrm{C}$ for $60 \mathrm{~min}$. Afterward, protein digestion was stopped by adding $30 \mu \mathrm{L}$ of $30 \%$ trichloroacetic acid. Then, non-hydrolysed azocasein was precipitated by incubating the reaction mixture at $4{ }^{\circ} \mathrm{C}$ for $1 \mathrm{~h}$ and supernatant was collected by centrifugation in $16,000 \times \mathrm{g}$ for $10 \mathrm{~min}$. Seventy-five $\mu \mathrm{L}$ of supernatant and seventy-five $\mu \mathrm{L}$ of $1 \mathrm{~N} \mathrm{NaOH}$ were mixed and measured at $450 \mathrm{~nm}$ with ELISA plate reader. For all assays, appropriate blanks were run.

\section{Serine protease assays (trypsin and chymotrypsin)}

In order to evaluate the trypsin and chymotrypsin (serine proteases), $10 \mu \mathrm{L}$ of extract and $5 \mu \mathrm{L}$ of substrate solution were added ( $1 \mathrm{mM}$ concentration) to $85 \mu \mathrm{L}$ of universal buffer ( $\mathrm{pH} 2$ to 12) and was evaluated using ELISA plate reader at 405 nm. N-benzoyl-arginine-p-nitroanilide (BApNA) and N-succinyl-alanine-alanineprolin-phenylalanine-p-nitroanilide (SAA PFpNA) (final concentration of $1 \mathrm{mM}$ ) were used to evaluate the trypsin and chymotrypsin, respectively. The substrates containing p-nitroanilide (pNA) released after enzyme digestion was recorded by ELISA plate reader at $405 \mathrm{~nm}$. Since the substrates had low solubility, dissolution of possible precipitants was performed by using $20 \mathrm{mM}$ dimethyl sulfoxide. Estimation of optimum temperature and $\mathrm{pH}$ were made within the temperature range from 10 to $90{ }^{\circ} \mathrm{C}$ and $\mathrm{pH}$ range from 2 to 12 . The thermal stability was investigated by measuring the residual activity of the enzymes after $15 \mathrm{~min}$ of incubation at different temperatures prior to substrate addition (Erlanger et al., 1961; 1964).

\section{Protease inhibitors assay}

The type of protease was determined with inhibitors for definition of protease classes and azocasein as substrate (da Silva-Lopez \& Giovanni-De-Simone, 2004). The proteases inhibitors, i.e. phenylmethylsulfonyl fluoride (PMSF, $5 \mathrm{mM}$ ), pepstatin $(10 \mu \mathrm{M})$ and ethylenediaminetetraacetic acid (EDTA, $10 \mathrm{mM}$ ) were added to $15 \mu \mathrm{L}$ extract separately (the inhibitors were added to the extract 15 min before incubation with azocasein) with $30 \mu \mathrm{L} 2 \%$ azocasein and $90 \mu \mathrm{L}$ universal buffer and incubated at $36^{\circ} \mathrm{C}$ for 60 min in parallel with a control group. Protein digestion was stopped by addition of $30 \mu \mathrm{L} \mathrm{30 \%} \mathrm{trichloroacetic} \mathrm{acid.} \mathrm{Non-}$ hydrolysed azocasein was also precipitated at $4{ }^{\circ} \mathrm{C}$ for one hour and the supernatant collected after centrifugation at $16,000 \times \mathrm{g}$ for $10 \mathrm{~min}$. Light absorbance of the mixture of supernatant $(75 \mu \mathrm{L})$ and $1 \mathrm{~N}$ $\mathrm{NaOH}(75 \mu \mathrm{L})$ was measured at $450 \mathrm{~nm}$.

\section{Statistical analysis}

All data are reported as mean \pm SD. GraphPad PRISM $®$ software (version 5.04, GraphPad Software, Inc. USA) was used for evaluation of the findings.

\section{RESULTS}

\section{Protease activity}

The total protein of the extract of the eggs was $0.233 \pm 0.03 \mathrm{mg} / \mathrm{mL}$. Due to the concentration of the total protein in the extract, we had approximately 1,000 Fasciola eggs per sample ground in liquid nitrogen. The proteolytic activity and the $\mathrm{pH}$ dependence using azocasein as substrate is demonstrated on Fig. 1. The azocasein was hydrolysed in a wide range of pH $2(5.5 \%)$ to $\mathrm{pH} 12$ (17\%). The maximum proteolytic activity of the eggs ex- 
tract was at $\mathrm{pH}$ 5. The highest activity of the enzyme was approximately preserved at $\mathrm{pH} 4-6(76 \%$ at $\mathrm{pH} 4)$ (Fig. 1).

On all following figures, the maximum OD is considered as $100 \%$ and data are expressed relative to maximum OD.

Serine proteases (trypsin, chymotrypsin)

The content of the eggs extract showed trypsin and chymotrypsin activities. Maximum activity toward BApNA was at $\mathrm{pH}$ $10(\mathrm{pH} 7-11)$ and $95.53 \%$ activity at $\mathrm{pH} 9$ (Fig. 2). The extract also had the highest activity toward SAAPFpNA at $\mathrm{pH} 8(\mathrm{pH}$ $7-10$ ) and more than $95 \%$ activity at $\mathrm{pH} 9$ and 10 (Fig. 3).
Fig. 4 shows the optimum temperature curves for trypsin and chymotrypsin protease activities. The two proteases had the same maximum temperature activity at $50{ }^{\circ} \mathrm{C}$, and the activity of trypsin quickly declined at a higher extent than the activity of chymotrypsin as temperature increased. The effect of temperature on the stability of trypsin and chymotrypsin was examined (Fig. 5). The two proteases were stable up to $40{ }^{\circ} \mathrm{C}$, followed by a decrease in activity with increasing the temperature. Also, chymotrypsin was more resistant to high temperatures compared to trypsin.

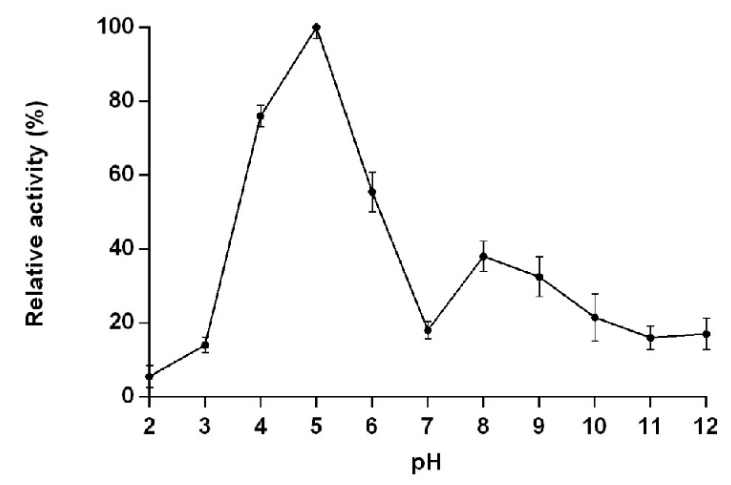

Fig. 1. Total proteolytic activity (mean $\pm \mathrm{SD}$ ) of Fasciola hepatica eggs extract at different $\mathrm{pH}$ levels by use of azocasein.

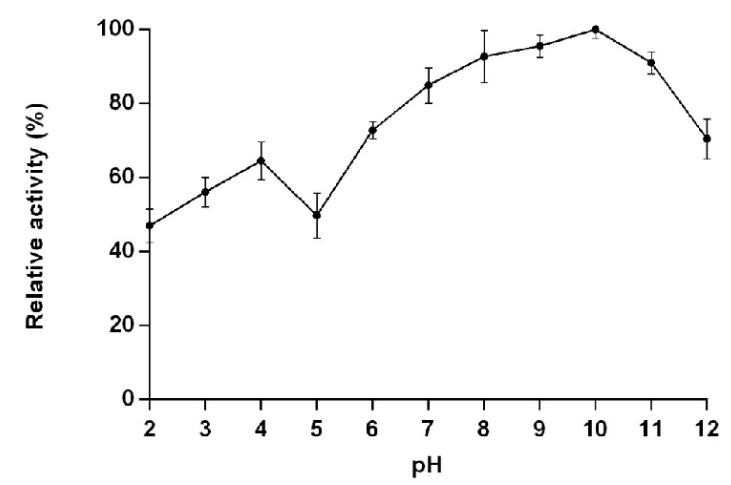

Fig. 2. Trypsin activity (mean $\pm \mathrm{SD}$ ) of Fasciola hepatica eggs extract at different $\mathrm{pH}$ levels by use of BapNA. 


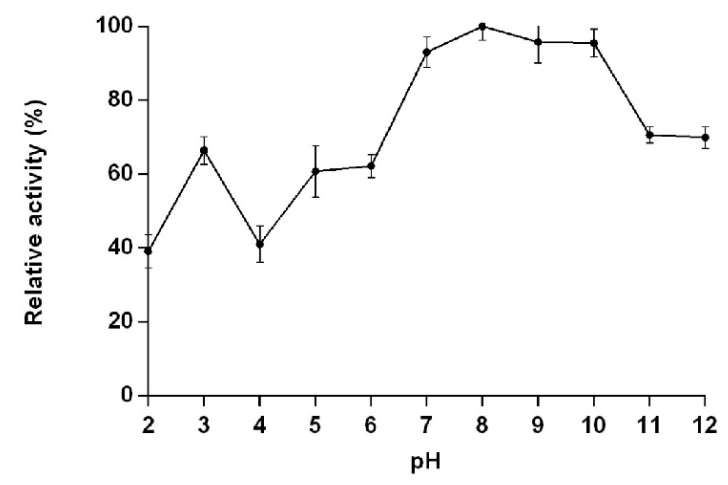

Fig. 3. Chymotrypsin activity (mean $\pm \mathrm{SD}$ ) of Fasciola hepatica eggs extract at different $\mathrm{pH}$ levels by use of SAAPFpNA.

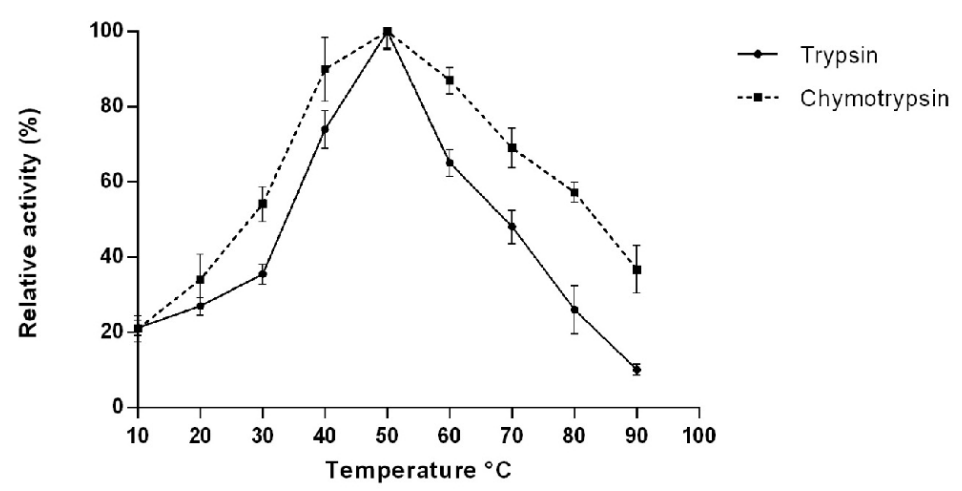

Fig. 4. Optimum temperature of trypsin and chymotrypsin protease activities of Fasciola hepatica eggs extract (mean $\pm \mathrm{SD}$ ).

\section{Protease inhibitors}

Table 1 shows the effect of protease inhibitors on protease activity. The inhibitory effect was $53.3 \%, 9.1 \%$ and $3.5 \%$ for PMSF, pepstatin and EDTA, respectively. PMSF demonstrated good inhibitory potential for serine protease with over $50 \%$ reduction in activity. The aspartate protease inhibitor, pepstatin and EDTA, which inhibits metallopeptidases had a poor effect.

\section{DISCUSSION}

In this study, the proteolytic activity of the extract of $F$. hepatica eggs was investigated and its inhibitory pattern was described by protease inhibitors. The results of this study showed that the proteases from eggs extract hydrolysed azocasein in a wide range of different $\mathrm{pH}$ values, and 


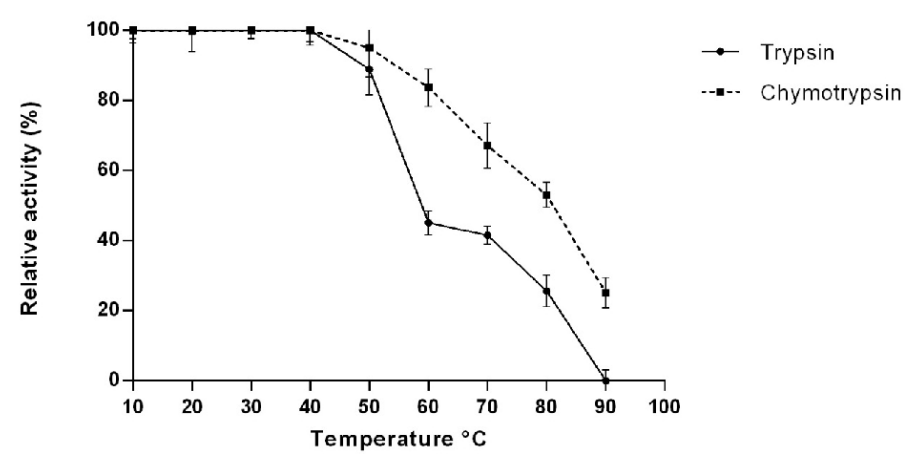

Fig. 5. Temperature stability of trypsin and chymotrypsin protease activities of Fasciola hepatica eggs extract $(m e a n \pm \mathrm{SD})$

Table 1. The effect of protease inhibitors on of the protease activity from the extract of the eggs of F. hepatica $($ mean $\pm \mathrm{SD})$

\begin{tabular}{llcc}
\hline Type of target protease & Inhibitors & Concentration & Residual activity (\%) \\
\hline Serine protease & PMSF & $5 \mathrm{mM}$ & $46.7 \pm 2.4$ \\
Aspartic protease & Pepstatin & $10 \mu \mathrm{M}$ & $90.9 \pm 4.9$ \\
Metalloprotease & EDTA & $10 \mathrm{mM}$ & $96.5 \pm 3.1$ \\
\hline
\end{tabular}

PMSF=phenylmethylsulfonyl fluoride; EDTA= ethylenediaminetetraacetic acid

the maximum proteolytic activity was in acidic $\mathrm{pH}$. However, substrates BApNA and SAAPFpNA were more specialised for demonstrating trypsin and chymotrypsin protease activities respectively. In this study, by use of the above mentioned specific substrates and protease inhibitors, it seemed that eggs of $F$. hepatica contained trypsin and chymotrypsin proteases.

The results of this study showed that the optimum $\mathrm{pH}$ of trypsin and chymotrypsin proteases was in alkaline $\mathrm{pH}$, which was near to the $\mathrm{pH}$ optimum for serine protease from Fasciola gigantica (Mohamed et al., 2005). In another study on adult $F$. gigantica, the maximum proteolytic activity was observed at $\mathrm{pH}$ 4-6 while, some activities were also shown at alkaline pH 10 (Fagbemi \& Hillyer, 1992). Accordingly, cysteine protease inhibitors had the highest inhibitory effect on proteolytic activity. The PMSF had a $37 \%$ and the pepstatin had $14 \%$ inhibitory effect on aspartate protease while the EDTA did not inhibit proteolytic activity. The study in $F$. gigantica with serine protease inhibitors, the PMSF and pepstatin, an aspartate protease inhibitor, demonstrated that some of the serine protease and aspartate protease activity existed in $F$. gigantica (Fagbemi \& Hillyer, 1992). It has been reported that the purified protease from adult $F$. hepatica had homogeneity at $14.5 \mathrm{kDa}$ (Rege et al., 1989). The inhibition of proteases activity by leupeptin and PMSF indicated that most of them were cysteine or serine proteases. This was in agreement with Dalton \& Heffernan (1989). The results of this study suggested that, while the extract of eggs 
was inhibited by PMSF, pepstatin and EDTA showed poor effect in inhibiting the proteolytic activity.

Determination of the type of proteases was studied by the use of specific inhibitors. Serine proteases are inhibited by serine protease inhibitors (da Silva-Lopez \& Giovanni-De-Simone, 2004). In the current study, we demonstrated serine protease activity in the extract of $F$. hepatica eggs. In contrast, previous reports demonstrated that all released proteases from $F$. hepatica were cysteine proteases (Dalton \& Heffernan, 1989). Both serine proteases and aspartate proteases were reported in $F$. hepatica (Rupova \& Keilova, 1979). The study on adult $F$. hepatica showed that the PMSF has a less inhibitory effect on proteolytic activity, and EDTA didn't reduce protease activity (Wijffels, 1994).

The results of the current study demonstrated that trypsin and chymotrypsin had the same maximum temperature activity at $50{ }^{\circ} \mathrm{C}$ in agreement with findings related to $F$. gigantica (Mohamed et al., 2005). The activity of trypsin quickly declined at a higher extent than that of chymotrypsin when the temperature increased. Trypsin and chymotrypsin proteases were stable up to $40{ }^{\circ} \mathrm{C}$, followed by a decrease in activity with increasing of temperature that was near to the thermal stability of serine proteases from $F$. gigantica (Mohamed et al., 2005). In addition, chymotrypsin was more resistant toward high temperatures compared to trypsin. The lower optimal temperature $\left(28^{\circ} \mathrm{C}\right)$ was reported for serine protease from $L$. amazonensis and the thermal stability indicated that $50 \%$ of the enzymatic activity was preserved after $4 \mathrm{~min}$ of pretreatment at $42{ }^{\circ} \mathrm{C}$ and after $24 \mathrm{~h}$ at $37^{\circ} \mathrm{C}$, both in the absence of substrate (da SilvaLopez \& Giovanni-De-Simone, 2004).
The study of the cathepsin-L1 stability in $F$. hepatica demonstrated that the enzyme retained $100 \%$ of its activity at $37{ }^{\circ} \mathrm{C}$ for $24 \mathrm{~h}$ (Dowd et al., 2000).

The results of this study showed that the eggs of Fasciola hepatica had trypsin and chymotrypsin activity. Future studies may elucidate their specific role in fasciolosis. According to the importance of $\mathrm{pH}$ and temperature in the life cycle of $F$. hepatica, determination of the optimum $\mathrm{pH}$ and temperature of activity of the eggs of this parasite could help to increase the effectiveness of protease inhibitors for reduction of embryonic development and egg hatching. Also, considering that the transmission of fasciolosis is favoured by the contamination of pastures with viable eggs, the possible effects of the antifertility effect that a given protease inhibitor could provide might prevent disease transmission and therefore decrease the prevalence of fasciolosis in endemic areas.

\section{ACKNOWLEDGEMENTS}

This work was financially supported by the office of vice chancellor for research and technology of Urmia University.

\section{REFERENCES}

Bradford, M. M., 1976. A rapid and sensitive method for the quantitation of microgram quantities of protein utilizing the principle of protein-dye binding. Analytical Biochemistry, 72, 248-254.

Carmona, C., A. J. Dowd, A. M. Smith \& J. P. Dalton, 1993. Cathepsin L proteinase secreted by Fasciola hepatica in vitro prevents antibody-mediated eosinophil attachment to newly excysted juveniles. Molecular and Biochemical Parasitology, 62, 9-17.

Da Silva-Lopez, R. E. \& S. Giovanni-DeSimone, 2004. Leishmania (Leishmania) 
amazonensis: purification and characterization of a promastigote serine protease. Experimental Parasitology, 107, 173-182.

Dalton, J. P. \& M. Heffernan, 1989. Thiol proteases released in vitro by Fasciola hepatica. Molecular and Biochemical Parasitology, 35, 161-166.

Dowd, A. J., M. Dooley, C. Fagain \& J. P. Dalton, 2000. Stability studies on the cathepsin L proteinase of the helminth parasite, Fasciola hepatica. Enzyme and Microbial Technology, 27, 599-604.

Dvorak, J., P. Fajtova, L. Ulrychova, A. Leontovyc, L. Rojo-Arreola, B. M. Suzuki, M. Horn, M. Mareš, C. S. Craik, C. R. Caffrey \& A. J. O'Donoghue, 2016. Excretion/secretion products from Schistosoma mansoni adults, eggs and schistosomula have unique peptidase specificity profiles. Biochimie, 122, 99-109.

Elpidina, E. N., K. S. Vinokurov, V. A. Gromenko, Y. A. Rudenskaya, Y .E. Dunaevsky \& D. P. Zhuzhikov, 2001. Compartmentalization of proteinases and amylases in Nauphoeta cinerea midgut. Insects Biochemistry and Physiology, $\mathbf{4 8}$, 206-216.

Erlanger, B. F., A. G. Cooper \& A. J. Bendich, 1964. On the heterogeneity of three-timescrystallized $\alpha$-chymotrypsin. Biochemistry, 3, 1880-1883.

Erlanger, B. F., N. Kokowsky \& W. Cohen, 1961. The preparation and properties of two new chromogenic substrates of trypsin. Archive of Biochemistry and Biophysics, 95, 271-278.

Fagbemi, B. O. \& G. V. Hillyer, 1992. The purification and characterization of a cysteine protease of Fasciola gigantica adult worms. Veterinary Parasitology, 43, 223232.

Horn, M., P. Fajtova, L. Rojo Arreola, L. Ulrychova, P. Bartosova-Sojkova, Z. Franta, A. V. Protasio, D. Opavsky, J. Vondrasek, J. H. McKerrow, M. Mares \& C. R. Caffrey, 2014. Trypsin- and Chymotrypsin-like serine proteases in Schistosoma mansoni- 'the undiscovered country'.
PLOS Neglected Tropical Diseases, 8, e2766.

Hurtrez-Boussès, S., C. Meunier, P. Durand \& F. Renaud, 2001. Dynamics of host parasite interactions: the example of population biology of the liver fluke (Fasciola hepatica). Microbes and Infection, 3, 841849.

Johnston, K. A., M. J. Lee, C. Brough, V. A. Hilder, A. M. R. Gatehouse \& J. A. Gatehouse, 1995. Protease activities in the larval midgut of Heliothis virescens: Evidence for trypsin and chymotrypsin-like enzymes. Insect Biochemistry and Molecular Biology, 25, 375-383.

Mas-Coma, S., 2005. Epidemiology of fascioliasis in human endemic areas. Journal of Helminthology, 79, 207-216.

McVeigh, P., A. G. Maule, J. P. Dalton \& M. W. Robinson, 2012. Fasciola hepatica virulence-associated cysteine peptidases: A systems biology perspective. Microbes and Infection, 14, 301-310.

Mohamed, S. A., A. S. Fahmy, T. M. Mohamed \& S. M. Hamdy, 2005. Proteases in egg, miracidium and adult of Fasciola gigantica. Characterization of serine and cysteine proteases from adult. Comparative Biochemistry and Physiology Part B: Biochemistry and Molecular Biology, 142, 192-200.

Rawlings, N. D., A. J. Barrett \& R. Finn, 2016. Twenty years of the MEROPS database of proteolytic enzymes, their substrates and inhibitors. Nucleic Acids Research, 44, D343-350.

Rege, N. N., H. M. Nazareth, A. Isaac, S. M. Karandikar \& S. A. Dahanukar, 1989. Immunotherapeutic modulation of intraperitoneal adhesions by Asparagus racemosus. Journal of Postgraduate Medicine, 35, 199-203.

Robinson, M. W., R. Menon, S. M. Donnelly, J. P. Dalton \& S. Ranganathan, 2009. An integrated transcriptomics and proteomics analysis of the secretome of the helminth pathogen Fasciola hepatica: Proteins associated with invasion and infection of the 
Activity of serine proteases from Fasciola hepatica eggs in relation to $\mathrm{pH}$ and temperature

mammalian host. Molecular Cell Proteomics, 8, 1891-1907.

Rupova, L. \& H. Keilova, 1979. Isolation and some properties of an acid protease from Fasciola hepatica. Zeitschrift für Parasitenkunde, 61, 83-91.

Sajid, M. \& J. H. McKerrow, 2002. Cysteine proteases of parasitic organisms. Molecular and Biochemical Parasitology, 120, 121.

Tallima, H., J. Dvorak, S. Kareem, M. Abou El Dahab, N. Abdel Aziz, J. P. Dalton \& R. El Ridi, 2017. Protective immune responses against Schistosoma mansoni infection by immunization with functionally active gut-derived cysteine peptidases alone and in combination with glyceraldehyde 3-phosphate dehydrogenase. PLOS Neglected Tropical Diseases, 11, e0005443.

Wijffels, G. L., L. Salvatore, M. Dosen, J. Waddington, L. Wilson, C. Thompson, N. Campbell, J. Sexton, J. Wicker, F. Bowen, T. Friedel \& T. W. Spithill, 1994. Vaccination of sheep with purified cysteine proteinases of Fasciola hepatica decreases worm fecundity. Experimental Parasitology, 78, 132-148.
Yakhchali, M. \& K. Bahramnejad, 2016. Inhibition effect of $\mathrm{pH}$ on the hatchability of Fasciola miracidia under laboratory conditions. Iran Journal of Parasitology, 11, 30-34.

Yang, Y., Y. J. Wen, Y. N. Cai, I. Vallée, P. Boireau, M. Y. Liu \& S. P. Cheng. 2015. Serine proteases of parasitic helminths. Korean Journal of Parasitology, 53, 1-11.

Paper received 02.10.2018; accepted for publication 18.01.2019

\section{Correspondence:}

Leila Kianifard

Department of Pathobiology, Faculty of Veterinary Medicine,

Urmia University, Urmia, Iran

PO Box: 5756151818

tel: +98 4432752741

e-mail: leilakianifard@gmail.com 